\title{
REALISMO INTERNO COMO REALISMO PRAGMATISTA E O ESQUEMA CONCEITUAL: UMA PROPOSTA CRÍTICA À METAFÍSICA TRADICIONAL
}

\author{
Alexandre de Freitas de Mello Júnior ${ }^{1}$ \\ Universidade Federal de Minas Gerais (UFMG) \\ (D) https://orcid.org/0000-0003-1312-2798
}

\begin{abstract}
RESUMO:
O objetivo desse artigo é evidenciar que o realismo interno pode ser um arcabouço teórico capaz de garantir que haja objetividade nos contextos linguísticos que estruturam nossas inter-relações comunitárias. Isso é parte de um projeto que Putnam tem desenvolvido desde a metade da década de 1970 e que, se lograr êxito, poderá ajudar a solucionar, a uma só vez, os problemas suscitados pelo relativismo cultural e dar um encaminhamento programático no que se refere à viabilidade de compreensão da realidade social e política em que está assentado o Ocidente, no que concerne à condição irreversível do pluralismo contemporâneo. Desse modo, nosso intuito será o de deixar evidenciado que é possível haver objetividade fundamentada em uma alternativa moderada do realismo que rejeita o realismo da metafísica tradicional e também as consequências mais comuns desse alijamento, qual seja, o relativismo cultural.
\end{abstract}

PALAVRAS-CHAVE: Realismo; Metafísica; Esquemas conceituais; Relativismo cultural.

\section{INTERNAL REALISM AS PRAGMATIST REALISM AND THE CONCEPTUAL SCHEMES: A CRITICAL PROPOSAL TO TRADITIONAL METAPHYSICS}

\begin{abstract}
:
The aim of this paper is to show that the internal realism may be a theoretical framework able to ensure that there is objectivity in linguistic contexts that shape our community interrelations. This is part of a project that Putnam has developed since the mid-1970s and that, if successfully

\footnotetext{
${ }^{1}$ Doutorando em filosofia pela Universidade Federal de Minas Gerais (UFMG), Minas Gerais - Brasil. E-mail: alexandremellounb@gmail.com
} 
achieve, may help solve, the one time, the problems raised by cultural relativism and give a programmatic routing with regard to viability of understanding of the social and political reality in which sits the West, regarding the irreversible condition of contemporary pluralism. Thus, our goal will be to make evident that there can be grounded in a moderate alternative to realism that rejects realism of traditional metaphysics and also the most common consequences of dumping, namely cultural relativism objectivity.

KEYWORDS: Realism; Metaphysics; Conceptual schemes; Cultural relativism.

\section{Introdução}

Em 1977, Hilary Putnam esboçou uma primeira formulação sucinta do que é conhecido atualmente como "realismo interno" em seu artigo intitulado Realism and Reason. Ele escreveu, em 1999, que havia chamado de 'realismo interno' a posição que defendera, tempos atrás, em seu famoso artigo The meaning of meaning, publicado originalmente em 1975, e que um sem-número de pessoas começaram a chamar esse 'realismo interno' de a nova posição de Putnam (2008c, p. 33). Ele mesmo reconheceu que a expressão era confusa, e em 1987 afirmou que deveria tê-la chamado de 'realismo pragmático' (1994, p. 61). Falaremos mais adiante sobre o motivo da confusão e porque preferimos, tal como Putnam, a nomenclatura 'realismo pragmático'.

Naquela definição originária, Putnam afirma que nessa espécie de realismo "não é a linguagem que espelha o mundo, mas que os falantes espelham o mundo" e que se trata "da relação dos falantes com seu ambiente, e do papel da linguagem" no que a isso concerne (1977, p. 483). Aqui temos algo que será amplamente desenvolvido, a saber, o papel do usuário de uma linguagem na constituição especular do mundo, e Putnam afirma que esse espelhamento tem o sentido de "construção de uma representação simbólica desse ambiente" (idem); e a relação entre mundofalantes-linguagem, que é o tripé sobre o qual repousará essa nova visão de realismo.

O realismo interno objeta as principais características da metafísica tradicional, e o faz por flagrante incompatibilidade dos pressupostos que fundamentam a ambos. O realismo interno denega correspondência exata que hipoteticamente há entre nós e o mundo. Essa correspondência exata é algo que não tem sentido para um realista interno. $O$ sentido da correspondência unívoca entre linguagem e mundo está estruturada do seguinte modo: Para haver correspondência exata (ou unívoca) entre nosso vocabulário e o mundo, precisaríamos da possibilidade de uma linguagem ideal que pudesse se referir ao mundo tal como ele é. Caso contrário, se 
nossa linguagem não fosse ideal, nossas designações linguísticas sempre estariam continuamente sujeitas a aperfeiçoamentos e fora da possibilidade de se referirem de forma unívoca ao mundo e, assim, de imprecisas que seriam, não nos poderiam auxiliar a descrever o mundo corretamente. Vamos analisar mais pormenorizadamente a crítica que Putnam lança a metafísica tradicional.

\title{
A crítica à metafísica tradicional
}

Essa última afirmação acerca da descrição correta da realidade nos remete à posição do realismo ${ }^{2}$ tradicional, assim denominada por Putnam, para o qual deve haver uma correspondência entre a realidade e as nossas tentativas de representar essa realidade tal como ela é. Desse modo, Putnam nos diz que:

\begin{abstract}
...se o realismo metafísico (tradicional) estiver certo, e se se pudesse ver o objetivo da ciência simplesmente como tentar conseguir que o nosso mundo nocional "correspondesse" ao mundo em si, então podia alegar-se que estamos interessados na coerência, abrangência, simplicidade funcional e eficácia instrumental apenas porque estas são instrumentos com o fim de realiza esta "correspondência". Mas a noção de correspondência transcendental e o mundo é em si um contrassenso. (PUTNAM, 1992, p. 174).
\end{abstract}

Putnam programa, a partir dessa consideração, encetar uma crítica ao realismo tradicional. Caso não o fizermos, teremos a permanência de problemas que gostaríamos de evitar, quais sejam, a noção de que os conceitos implícitos à investigação científica, os valores epistêmicos, são meramente convencionais, não sendo necessários senão para atender os nossos desideratos de correspondência à realidade unívoca; e a convicção de que "objetividade" é o mesmo que correspondência a objetos. Isso excluiria, de uma vez por todas, a tentativa de compreender os valores em seu aspecto cognitivo.

Destarte, para que possamos conferir aos enunciados avaliativos o caráter de cognitivos, devemos empreender uma reformulação à noção tradicional de objetividade, que é arrendatária dos pressupostos do realismo

\footnotetext{
${ }^{2}$ Segundo Simon Blackburn, "Um realista sobre um assunto A pode sustentar (I) que os tipos de coisas descritas por A existem; (II) que sua existência é independentes de nós, ou que não são objetos produzidos pela nossas mente, linguagem ou esquema conceitual; (III) que as afirmação que fazemos em $\mathrm{A}$ não são redutíveis a outros tipos de afirmações eu possam afinal revelar ser acerca de outra coisa que não A; (IV) que as afirmações que fazemos em A têm condições de verdade, constituindo descrições inequívocas de aspectos do mundo, sendo verdadeiras ou falsas em função dos fatos do mundo; (V) que conseguimos obter verdades acerca de A, e que é apropriado acreditar completamente no que afirmamos em A”. (BLACKBURN, 1997, p. 335)
} 
tradicional. Ao criticar o realismo tradicional, Putnam irá nos fornecer instrumentos para alterarmos a noção de objetividade. $\mathrm{E}$, em não sendo objetivo somente o que é factual, depois das considerações sobre o realismo tradicional à noção de fato surge como interdependente de nossa linguagem, que é, a uma só vez, descritiva e avaliativa. Comecemos, então, a crítica de Putnam ao realismo tradicional.

A crítica de Putnam ao realismo tradicional inicia-se com a identificação de que uma das suas questões problemáticas consiste em pensar-se, segundo suas próprias palavras, "que existe uma totalidade de Formas, ou Universais ou 'propriedades', estabelecida de uma vez por todas, e de que todos os significados possíveis de uma palavra correspondem a uma dessas formas ou Universais ou propriedades" (2008c, p. 19). Putnam observa que o problema aqui patenteado diz respeito ao significado. Pensa-se, em geral, que o significado das palavras designa uma propriedade a qual estas palavras referem-se, de modo que uma palavra tem como função apreender o mundo tal como ele é, com suas propriedades intrínsecas.

Putnam supõe o exemplo das espécies naturais, salientando que todas as amostras de ouro puro, bem como os objetos forjados com ouro puro, possuem em comum a propriedade de constituírem-se de isótopos do elemento atômico de número 79. Entretanto, Putnam está convencido de que a palavra ouro não é sinônima de "elemento atômico de número 79". Isso ocorre porque o significado cotidiano da palavra 'ouro' não pode ser definido como uma propriedade ou conjuntos de propriedades. Wittgenstein $^{3}$ corrobora a ideia de que fazemos uso de vasta gama de palavras com respeito às quais não existem propriedades comuns a todos os objetos a que estas palavras se aplicam com correção.

Desse modo, estabelece-se uma visão metafísica segundo a qual a realidade é apresentada como "um conjunto fixo de objetos 'independentes da linguagem' e uma 'relação' fixa entre os termos e suas extensões" (PUTNAM, 1999, p. 102). Putnam nos traz a reflexão de que os objetos não são independentes da linguagem, ao mesmo tempo em que afirma que a imagem de mundo "não é o produto da nossa vontade - nem das nossas disposições para falar de determinadas maneiras" (1999, p. 103). Com isso, Putnam está a dizer que a linguagem exerce a função de elaborar um vocabulário que possa estabelecer uma conexão com o mundo, vocabulário que pode ser melhor elaborado, com o fim de referir-se melhor do que antes aos objetos.

Podemos dizer que Putnam quer enfatizar a importância da linguagem em todo o trâmite da tarefa de representar o mundo. Na visão da metafísica tradicional, julga-se que a linguagem é impassível do ponto de vista da representação. Isso quer dizer que, frente ao mundo, a tarefa

\footnotetext{
${ }^{3}$ Ver a obra Investigações Filosóficas, de Wittgenstein.
} 
linguística consiste em estabelecer a função de designadora, sendo esta linguagem, porém, neutra. A neutralidade linguística dos termos que compõem a realidade implica uma imagem de mundo em que o instrumental fornecido pela linguagem serve meramente como expressão verbal de nossas impressões e representações.

Outra questão suscitada pela crítica ao mencionado tipo de realismo tradicional "é o pressuposto confortável de que há uma totalidade definida de objetos que pode ser classificada, bem como uma totalidade definida de todas as propriedades" (2008, p.19). A crítica de Putnam à definição peremptória do universo de objetos que podem ser referidos, e a coleção fixa de propriedades, pode levantar a falsa objeção segundo a qual o mundo é totalmente construído pelos indivíduos ${ }^{4}$. Todavia, Putnam observa que nossas pretensões de conhecimento se dirigem a uma realidade em geral independente dos indivíduos, ou melhor, dos falantes.

Embora Putnam corrobore a ideia de que há uma realidade independente dos falantes, ele está seguro de que "a reflexão sobre a experiência humana sugere que nem a forma de todas as alegações de conhecimento nem os modos pelos quais elas são responsáveis perante a realidade são estabelecidos de antemão e de uma vez por todas" (2008, p. 20). Pode-se afirmar, portanto, que apesar de Putnam supor uma realidade em geral independente da mente, não há, com relação ao projeto humano acerca do conhecimento, uma independência concernente ao modo e à forma de nossas alegações cognitivas. Se isto não estiver correto, podemos estabelecer a noção rejeitada por Putnam, segundo a qual existe um número delimitado de propriedades que devemos simplesmente "descortinar", "descobrir" e, feito isso, usarmos tais propriedade para denotar os objetos constantes na realidade, que por sua vez são também delimitados e fixos.

Mas a que tipo de objetos o realista tradicional se refere? Putnam afirma que "As formas tradicionais de realismo estão comprometidas com a alegação de que faz sentido falar de uma totalidade estabelecida de todos os 'objetos' a que nossas proposições podem referir-se" (2008, p.20). Embora isso seja dito, a pergunta continua em aberto. Putnam interroga se um evento histórico, como a Segunda Grande Guerra, é um objeto. Do mesmo modo, o céu é um objeto? Ou a imagem que percebemos no espelho é um objeto? Teríamos que atentar para os critérios estabelecidos pelo metafísico tradicional e, assim, identificarmos o que seria um típico objeto nessa ontologia.

\footnotetext{
${ }^{4}$ Para maiores elucidações a essas críticas feitas a Putnam, ver BOGHOSSIAN, Paul. Medo do conhecimento: contra o relativismo e o construtivismo, 2012, pp. 61-63. São Paulo: editora senac. Esta contestação de Boghossian toma como exemplo a noção de descrição da realidade constante na obra de Putnam Realismo de Rosto Humano, capítulo 6, intitulado Verdade e Convenção. Falar-se-á a respeito dessas críticas quando comentarmos o caráter não relativista do realismo interno.
} 
Putnam nos diz que o problema sobre objetos está posto antes mesmos de supormos a existência de entidades como as que postulamos acima, dado o antigo critério de individualidade de um objeto, qual seja, o de que suas partes acompanham o movimento do objeto quando este se deslocar. Putnam obtempera que há objetos de existência inquestionável que infringem este critério e afirma: "tenho em casa uma lamparina que viola este critério; a sombra diminui sempre que a lamparina se desloca! Será que a lamparina neste caso não é um objeto?" (2008c, p. 21).

A resposta pode estar na noção de soma mereológica, na qual os objetos são, eles próprios, aditamentos de partes de outros objetos. Putnam supõe que a soma mereológica poderia solucionar o problema da lamparina, explicando o porquê de ela ser um objeto. Porém, ele destaca que as consequências podem ser fortes e os resultados muito caros: "Se a 'soma' de quaisquer dois (ou mais) objetos for um objeto; se houver até um 'objeto' formado pela minha orelha esquerda e o nariz do leitor, então existe de fato um objeto equivalente à soma mereológica do corpo da lamparina e da sombra" (2008c, p. 21).

Este exemplo levantado por somas mereológicas suscita uma modificação das concepções tradicionais acerca dos objetos e, mais ainda, da alegação de conhecimento possível que deles temos, e de que suas propriedades possíveis são passíveis de mudanças centrais. Segundo Putnam:

\section{O realista tradicional parte do princípio de que os nomes gerais correspondem, de maneira mais ou menos unívoca, a várias "propriedade" de "objetos", em algum sentido de "propriedade" e em algum sentido de "objeto" estabelecidos de uma vez por todas, e de que as alegações de conhecimento são simplesmente alegações sobre a distribuição dessas "propriedades nesses “objetos" (PUTNAM, 2008, p.22)}

Putnam considera que o realista tradicional está completamente certo em um ponto: ele tem a acertada convicção de que a realidade é independente, e que as descrições que dela fazemos e chamamos de 'mundo' devem manter uma espécie de responsabilidade cognitiva. Em que pese essa imagem, não devemos a ela conectar a noção de que existe uma descrição ou descrições que estão postas de uma vez por todas, todas elas possíveis, e com as quais devemos nos referir, necessariamente, a essa mesma realidade. A afirmação seguinte de Putnam é que com esta imagem das descrições que a metafísica tradicional preconiza perdemos o mais importante e verdadeiro aporte do pragmatismo: "o de que a 'descrição' nunca é uma mera cópia e de que estamos sempre criando novas maneiras de a linguagem poder ser responsável perante a realidade" 5 (2008c, p. 22).

\footnotetext{
${ }^{5}$ Esse consideração é, segundo Putnam, inspirada em William James.
} 
Embora essa contribuição possa ser tomada de vários modos, tal como o próprio James $^{6}$ e Putnam o fizeram, esse diz que não estamos habilitados a concluir o mesmo que aquele, a saber, que nós criamos, em parte, o mundo. Ora, para Putnam a existência de uma realidade independente de nós é algo do qual não podemos duvidar a sério, e o simples fato de assumir isso já o coloca na categoria daqueles que aderem ao realismo. A característica agora enfatizada é a recusa da chamada ingenuidade do realismo tradicional, segundo a qual existe uma totalidade fixa de objetos e propriedades em cuja relação descobrimos as propriedade para denotar os objetos.

O que motiva esta dispensa da ingenuidade do realismo tradicional é a compreensão de que nossa linguagem e seu evidente uso estão colocados desde sempre, e que não devemos transigir com a ideia de que as propriedades, expressadas pelos conceitos, modos de referências, formas de descrições, apresentação de significados, etc., são imutáveis. Putnam esclarece sua posição da seguinte maneira:

\begin{abstract}
A ideia de que nossas palavras e nossa vida são constrangidas por uma realidade exterior a nós desempenha um importante papel em nossa vida e deve ser respeitada. A fonte de confusão reside no erro filosófico vulgar de se supor que o termo realidade tem de referir-se a uma única supercoisa, em vez de considerar as formas como renegociamos incessantemente - e somos forçados a renegociar - nossa noção de realidade à medida que nossa linguagem e nossa vida se desenvolvem. (PUTNAM, 2008, 23)
\end{abstract}

A esta crítica segue-se naturalmente o que Putnam nos trará, a saber, a constatação da ininteligibilidade da afirmação, feita pelo realista tradicional, de que há "uma nítida linha divisória entre as propriedades que 'descobrimos' no mundo e as que 'projetamos' no mundo" (2008, p. 35).

Isso significa que a realidade não possui termos próprios que podemos captar por meio de um processo de apreensão sígnico misterioso e, destarte, configurar uma noção de mundo que esteja a ela adequadamente acoplada em um sentido apenas em segunda instância linguístico. Seria só em segunda instância linguístico, pois o processo de captura da realidade "tal como ela é" não se daria à nossa compreensão por meio linguístico.

Este é o problema que está pressuposto na forma de acoplagem (o modo como a linguagem se conecta ao mundo) do realismo tradicional decorrente do que Putnam diz acima, qual seja, o de passarmos da apreensão das propriedades extralinguísticas da realidade para a conceituação semântica do mundo. $\mathrm{O}$ que pode ser evidenciado na passagem da percepção da realidade para a sua intelecção (linguística). A

\footnotetext{
${ }^{6}$ Ver o texto $O$ Empirismo Radical, de William James. Esse texto está relacionado na obra Pragmatismo e textos selecionados, arrolado na bibliografia desse trabalho.
} 
ininteligibilidade da "linha divisória", indistinta, não nos habilita a afirmar que o mundo não possui propriedades extrínsecas à mente humana. Esta conclusão seria uma extrapolação com a qual Putnam não se coaduna, pois sua consequência imediata é a recusa da existência de uma realidade independente de nossas descrições e conceituações.

O que a noção de ininteligibilidade da afirmação da linha divisória, com relação às propriedades "descobertas" e às propriedades "projetadas", enseja concluir, é que subjaz à interpretação da classe dessas propriedades o uso linguístico que nós criamos para nos referir a ambas. Se não há uma linguagem factual da natureza e, portanto, ela não possui termos intrínsecos com os quais devemos a ela nos referir, torna-se azado sugerir uma linguagem capaz de fazê-lo, linguagem esta que é consignada pelo uso que dela fazemos ${ }^{7}$.

Pode-se dizer, em uníssono com Putnam, que o que liga a crítica do realismo tradicional à reformulação do conceito de fato é a limitação que as tradicionais dicotomias "juízos de fato versus juízos de valor" e "verdades de fato versus verdades analíticas" promovem. É justamente a tomada de posição do realismo tradicional que irá contaminar o conceito de fato, fazendo deste um conceito que, em sua versão moderna, somente refere-se a objetos que podem ser percebidos pelos sentidos, deixando os valores relegados à subjetividade plena.

Segundo Putnam, estas dicotomias estanques "corromperam nosso pensamento, tanto no raciocínio ético como na descrição do mundo, principalmente, por impedir-nos de ver como a avaliação e a descrição estão interconectadas e são interdependentes" (2008a, p. 15). A limitação se sobrepõe ao conteúdo filosófico e torna-se consagrada. O esforço de Putnam em buscar um novo tipo de realismo que se preste a uma explicação heterodoxa de como nos relacionamos com o mundo nos é importante porque ela necessariamente reformula aspectos da metafísica tradicional, lançando-lhe as bases para uma contestação do conceito de objetividade que se consolidou na história da filosofia, desde a filosofia moderna ${ }^{8}$.

${ }^{7}$ Não haver uma linguagem própria à natureza, com a qual poderíamos nos referir a ela perfeitamente, caso conseguíssemos fazer uso de tal linguagem, não nos coloca na difícil situação na qual não podemos nos referir com precisão à realidade: apenas teremos, para descrever e denotar as propriedades da natureza, que fazer uso de uma terminologia que não é intrínseca à realidade, mas a qual ela se refere e por ela é motivada efetivamente. Podemos afirmar que os termos que usamos para nos referir à natureza lhe são extrínsecos, embora se refiram a ela, sempre com maior ou menor grau de precisão, e por ela são motivados. Por isso, a nós, na acepção linguística, cabe "renegociar" nossos termos de referência (PUTNAM, 2008c, p. 23).

${ }^{8}$ A dificuldade que se tem ao tentar conectar as questões clássicas do realismo tradicional a uma análise de sua influência nas questões de valor (ético) está posta pela falta de acuidade que temos, pois não damos importância suficiente àquilo que as une - trata-se de uma polarização, também estanque, entre objetividade e subjetividade. Uma tomada de posição inovadora com relação ao realismo implicará outro ponto de vista concernente à objetividade, pois teremos que atenuar, no caso específico de Putnam, a linha entre a 
Passemos à análise sobre o pressuposto último do realismo tradicional criticado por Putnam, a saber, que há "uma relação fixa de 'correspondência' em termos da qual se supõe que a verdade seja definida" (2008c, p.35). Putnam nos lembra, após mencionar o pressuposto do realismo, que sua rejeição está caracterizada pela ininteligibilidade dessa afirmação. Este pressuposto parece resumir, de algum modo, todos os pressupostos anteriormente mencionados, cujos apanágios são: a fixidez das formas predicativas da linguagem, e a consequente fixidez das interações entre os aspectos da realidade e a mente; e a possibilidade de nos referirmos aos objetos do mundo não só de modo adequado, mas de modo unívoco, a que se segue uma capacidade de podermos fazer corresponder nossos enunciados linguísticos a tais objetos, desembocando em uma teoria da verdade por correspondência unívoca.

A rejeição, ou declaração de ininteligibilidade dos pressupostos da metafísica do realismo tradicional é, necessariamente, uma recusa da noção de verdade que destes pressupostos decorrem. Se considerarmos que a noção de fato tem estado intimamente relacionada com ao menos um desses pressupostos, estaremos afirmando que o 'fato' conecta-se àquilo que no realismo tradicional chama-se objeto. Apesar de toda a discussão em torno do que é um objeto, sabemos que na história da filosofia há uma relação de proximidade indesvencilhável entre fato e objeto, pois só poderia ser factual o que é objetual. Ao contrário, o subjetivo não poderia ser um fato. A crítica de Putnam é dirigida ao realismo tradicional e à absorção de algumas das decorrências desse realismo pelo empirismo humeano - como a noção tradicional de fato ${ }^{9}$ e a representação dos objetos como cópia, proporcionada a partir do aparato sensorial.

Como vimos, para localizar o lugar dos valores e dos fatos na dicotomia tivemos que reorientar essas noções. Putnam nos apresenta uma crítica ao realismo tradicional, mas não nega que possamos almejar um tipo de adequação ao mundo empírico:

... usamos os nossos critérios de aceitabilidade racional para construir um quadro teórico do "mundo empírico", e então à medida que essa imagem se desenvolve revemos os nossos próprios critérios de aceitabilidade racional à luz desse quadro e assim por diante, e assim por diante sempre (PUTNAM, 1992, p. 174).

objetividade e a subjetividade para darmos conta dos aspectos perceptivos com relação ao mundo ou, em outras palavras, para conseguirmos explicar a relação entre a mente e o mundo. Está patente que nos interessa enfatizar os tópicos que poderão nos fornecer o instrumental necessário para seguir o argumento de Putnam, e que a linguagem exerce um papel fundamental que estará no centro da compreensão putnamiana da verdade. Temos, neste momento, a sua crítica ao realismo tradicional.

9 Corroborada, posteriormente, por características típicas do empirismo, como, por exemplo, os dados dos sentidos. 
Podemos perceber que um dos resultados da crítica de Putnam ao realismo tradicional é que nossa linguagem pode ser indefinidamente melhorada para nos referirmos ao mundo empírico, mundo esse externo e independente de nós. Embora essa independência (enquanto existência do mundo externa à mente humana) seja algo patente, a respeito do qual Putnam não contrapõe nenhum argumento, ele sublinha o papel da linguagem no mundo real. Desse modo, o mundo real, formado pelos objetos aos quais nos referimos, é moldado segundo nossos critérios de aceitabilidade racional, propostos por nossa linguagem.

A conclusão a que Putnam chega é a seguinte: nosso vocabulário é como que constrangido pelo mundo empírico, e não é uma criação aleatória e unilateral, pois o mundo participa da formação desse vocabulário. Porém, nosso enquadramento do mundo real não é indiferente e impassível a esse mesmo vocabulário e, uma vez que os nossos valores são a lente através das quais nós podemos visualizá-lo, esse enquadramento do mundo real depende dos nossos valores. Em suma, o mundo externo à nossa mente não depende de nossas considerações concernentes a ele para existir, mas o mundo, com seus objetos, depende de nossos valores para ser formado, haja vista que não existe uma linguagem independente de nós no mundo.

Ademais, Putnam declara que ao menos alguns dos valores epistêmicos têm que ser objetivos. Ele argumenta que aceitar racionalmente um determinado enunciado depende do pano de fundo constituído por valores epistêmicos, pois os enunciados cognitivos não podem ser formulados, significativamente, sem a adesão a termos valorativos (PUTNAM, 1992, p. 175). O imbricamento entre as noções de fato e valor nega que os enunciados factuais possam ser neutros. Afinal, a tese do imbricamento entre as noções de fato e valor repousa na revisão dos pressupostos do realismo tradicional, de modo que seria despropositado afirmar uma linguagem do mundo inteiramente factual, independente de nossos usos e aplicações conceituais (PUTNAM, 2008a, p. 147).

Se aceitarmos a crítica ao realismo tradicional em pelo menos uma de suas considerações, o teremos suficientemente fragilizado para podermos afirmar, depois de tudo exposto, que o modo de falarmos sobre a realidade exterior depende de conceitos por nós aplicados a ela. Não obstante, esses conceitos são suscitados pela pressão dessa realidade exterior que, assim, corrobora sua formação, e, portanto, não são meramente casuais ou convencionais. $\mathrm{O}$ fato de nossos usos e aplicações de conceitos se referirem a uma realidade exterior independente de nós quer dizer, a uma só vez, que não há algo como propriedades de objetos independentes de nossa linguagem (2008a, p. 23); e também que nossa linguagem conceitual referese a características dessa realidade exterior (PUTNAM, 1992, p. 176).

De acordo com isso, podemos dizer que termos avaliativos como "coerente", "simples", etc., não são destituídos de uma aplicação que se 
relaciona com a realidade, visto que no tocante à aplicação desses termos há uma importante "adequação" a essa realidade mesma. Aplicar um conceito é, dessa maneira, adequá-lo àquilo que é referido não unicamente de modo individual (o que culminaria em um subjetivismo de tipo solipsista), mas também de modo reconhecível, o que significa que a aplicação deve poder ser compreendida por outros usuários da linguagem, e não tão-somente pelo indivíduo que realiza (ou aciona) a aplicação imediata (1992, pp. 158-159).

Portanto, a tarefa de aplicar um termo avaliativo à realidade não é uma tarefa apenas subjetiva, pois, caso o fosse, poderíamos dizer que uma teoria qualquer é "coerente, para o indivíduo $x$ " e "não é coerente, para o indivíduo y". Porém, isso contraria a própria natureza do termo "coerente", pois há nesse termo uma reinvindicação que não é meramente a possibilidade de uso privado, mas, antes, a reinvindicação de uma aplicação conceitual que possa ser reconhecida por indivíduos em seu caráter intersubjetivo.

\section{Uma alternativa: o realismo interno, ou realismo pragmatista}

Por conseguinte, nós deveríamos almejar não simplesmente que nossa linguagem fosse melhor, mas, para representar o mundo como é devido, deveríamos desejar que ela tivesse um poder expressivo perfeito. $\mathrm{O}$ mundo "tal como ele é" reúne a totalidade finita de objetos do mundo, ou como Putnam os chama, "o mobiliário do mundo". Esse "mobiliário" é composto por objetos singulares possuidores de essências e características disposicionais que, quando são descobertas, podem ser nomeadas e comunicadas.

O mundo "tal como ele é" é composto por objetos fixos. A ideia de objetos fixos presume que o mobiliário do mundo está no âmbito da possibilidade de ter a totalidade de seus objetos representados e captados por nós pelo médium linguístico. Essa estrutura do mundo "em si" pode ser conhecida pela razão e transmitida pela linguagem, pois o logos filosófico tem que ser capaz de exprimir as verdades que estão claras na razão (DE OLIVEIRA, 2006, p. 126). Isso corrobora a ideia de que um mundo pronto está disponível epistemologicamente de maneira não refratária, bastando que seus objetos sejam acessados, ou melhor, descobertos pelas vias certas.

Segundo Putnam, "Não há nenhum ponto de vista do Olho de Deus que possamos conhecer ou imaginar proveitosamente" (1992, p. 72). O que é esse ponto de vista do "Olho de Deus"? A perspectiva do "Olho de Deus" sugere a possibilidade de representarmos $\mathrm{o}$ mundo sem que tal representação esteja conspurcada por nossas mediações humanas que, inevitavelmente, irão produzir uma deturpação dessa perspectiva pura. A perspectiva do "Olho de Deus" é a conjectura, tornada convicção, de que uma realidade independente de nós pode ser representada na medida dessa independência, e aquém desse nós. Isso significa que se pode conceber uma 
relação ideal de correspondência entre os humanos e a realidade independente sem que seja levado em consideração o lugar que ocupamos na realidade independente.

A perspectiva que o realismo interno procura instaurar é um ponto de vista telúrico, no qual a visada humana possa ser privilegiada. A ênfase da perspectiva do realismo interno não está em um ponto de vista que alije o papel do humano na configuração do real, mas, pelo contrário, o reforça. É importante notar que segundo Putnam, a perspectiva humana sobre a realidade é a única que nos está disponível (1992, p. 211).

Não há que se imaginar outro modo de percebê-la, e fazê-lo, negando a experiência da perspectiva de primeira pessoa, é estabelecer que a realidade é passível de uma compreensão neutral, a partir do "Olho de Deus", que prescinde da nossa visada humana. O Olho de Deus é o ponto de vista ideal da realidade a qual a perspectiva humana se resume a descrever, enquanto não interfere, tal como ela é. Assim, o "Olho de Deus" é a teoria da verdadeira única (PUTNAM, 1992, 102).

Ora, se estamos a falar que não há um ponto de vista privilegiado que nos garanta uma descrição de objetos e suas propriedades, ambos fixos, estamos a recusar um absoluto conceitual, em que está inclusa a possibilidade de descortinamento de um mundo pronto. Se não há esse ponto de vista privilegiado do mundo, como pode o realismo interno fundamentar a noção de objetividade?

Comecemos com uma afirmação de Putnam: "Se nossa 'objetividade' é objetividade humanamente falando, ainda é objetividade suficiente" (1992, p. 211). Isso quer dizer duas coisas principais. Primeiro, significa que no realismo interno há a confissão de que não detemos um ponto de vista neutral, e que o ponto de vista não-neutral é eminentemente humano. É a partir dessa perspectiva insuperável, o ponto de vista do agente humano, que podemos pronunciar nossas asseverações, e as marcas dessa visada humana estão em tudo aquilo que fazemos.

Segundo, quando abandonamos o ponto de vista do "Olho de Deus", isto é, a teoria da descrição unívoca, abandonamos a objetividade que a ela está articulada. Porém, não é necessário alijar a noção de objetividade, como em geral fazem aqueles que derrogam o ponto de vista do "Olho de Deus", e adotar o relativismo. Dito de outro modo, aquele que adota um ponto de vista diferente do apresentado pela metafísica tradicional não está fadado a abandonar o conceito de objetividade. Agora deveremos explicar como isso acontece.

Proporemos, para essa finalidade, o mesmo esclarecedor exemplo de qual Putnam se utiliza para levar adiante essa questão (2014, p. 170). Imaginemos que em uma casa entrem dois amigos, e que sua mobília aparente seja composta por uma cadeira, uma mesa e, em cima da mesa, uma lâmpada, um caderno e uma caneta. A pergunta lançada, um tanto quanto enigmaticamente por um dos dois amigos, é a seguinte: "Quantos 
objetos há na casa?", ao que o outro responde prontamente "Cinco objetos, e são eles a mesa, a cadeira, a caneta, o caderno e a lâmpada". O amigo que lançou a questão inicial prossegue: "E quanto a nós dois? Por acaso não estamos na casa?". O amigo que é interrogado responde, com surpresa: "Não sabia que você havia considerado que nós dois poderíamos ser contabilizados como objetos. Se é esse o caso, então o número total de objetos é sete". Entretanto, o amigo não se dá por satisfeito com as duas interrogações anteriores e volta à carga com uma terceira: "E o caderno que aqui temos? As páginas que lhe compõe não são objetos?".

Putnam imagina que uma resposta a essas questões está ligada profundamente a certos pressupostos que são assumidos pelos amigos. Se adotarmos certa espécie de modo de analisarmos as questões proposta, diremos que o número de objetos é 'cinco'; se adotarmos outro modo, o número de objetos pode parecer não contabilizável. Por exemplo: se considerarmos que os átomos que estão presentes na casa são objetos, certamente haverá dificuldade no estabelecimento de quantos objetos eles existem. Poder-se-ia fundamentar a tese de que átomos são objetos se assumíssemos a premissa de que toda entidade que pode ser o valor de uma variável ligada a um quantificador, ou seja, qualquer coisa a qual possamos nos referir utilizando um pronome é um objeto. Desse modo, os referidos átomos, tomados isoladamente, seriam miríades de objetos singulares, e na casa da qual falávamos haveria muito mais do que cinco ou sete objetos.

Caso rejeitássemos essa compreensão do que é um objeto, e assumíssemos outra versão de como eles são compostos, segundo a qual tal metafísica consideraria que há certas entidades são partes de objetos que, por sua vez, são configurados a partir da conjunção dessas partes, então nem todas as entidades que pudessem ser referidas pronominalmente seriam objetos, de modo que as páginas do caderno, por exemplo, seriam partes do objeto caderno, e não objetos singulares. Dissemos acima que embora alijássemos uma "teoria da verdade única", não extinguiríamos a noção de objetividade. Todavia, como está já evidenciado pela situação apresentada, a noção de objetividade de que falamos distingue-se por não poder ser independente.

Nas duas interpretações possíveis que aventamos para responder a pergunta "Quantos objetos existem na casa" o que garante uma resposta precisa é o uso que fazemos da palavra objeto (PUTNAM, 2014, p.174). É a partir do modo como entendemos os aspectos conceituais dos termos que usamos para nos referirmos as entidades que poderemos fixar alguma espécie de objetividade. Não é possível imaginar qualquer forma de objetividade na resposta a essa questão que prescinda da maneira como são aplicados os termos. A objetividade e, por consequência, a verdade dos enunciados dependem do uso dos termos. Putnam nos diz que: 


\begin{abstract}
... numa visão interiorista ${ }^{10}$ os signos não correspondem intrinsecamente aos objetos independentemente de como e por quem esses signos sejam empregues. Mas um signo que seja de fato empregue de um modo particular por uma comunidade particular de utentes pode corresponder a objetos particulares no interior do esquema conceitual desses utentes. Os "objetos" não existem independentemente dos esquemas conceituais. Nós retalhamos o mundo em objetos quando introduzimos um ou outro esquema de descrição (PUTNAM, 1992, p.80)
\end{abstract}

A citação acima pode esclarecer vários pontos do realismo interno. Primeiro, como já o temos dito, o uso e aplicação dos termos são condição presente para que se tenha a verdade ou a falsidade de um enunciado. A objetividade do termo necessita de um contexto no qual ele é empregado, e com isso se garante que o termo possua significado. Como Wittgenstein afirma, e Putnam parece estar de acordo, "O significado de uma palavra é seu uso na linguagem" (WITTGENSTEIN, 2009, p. 38).

Isso nos leva ao segundo ponto, a saber, o de que não há possibilidade de o uso estar desvinculado de uma comunidade de usuários de uma determinada linguagem. Ou seja, o uso ocorre no interior de um conjunto formado por termos e modos de referência que é desenvolvido ao longo das diversas situações históricas e culturais a que uma comunidade linguística pode estar submetida. Chama-se a esse cenário linguístico condicional de esquema conceitual.

Com a intrusão do conceito de "esquemas conceituais" a noção de "objeto" se aclara a partir da metáfora do molde de biscoitos: "As coisas, independentemente de toda eleição conceitual, são a massa; a forma do molde nossa contribuição conceitual" (PUTNAM, 1994, p. 174). As entidades a que chamamos de "objetos" podem ser consideradas assim não porque haja uma realidade objetual em si, mas porque nós recortamos a realidade com o fim de distinguirmos certas partes e, desse modo, podermos a elas nos referir. Por isso que Putnam afirma que não existem objetos independentes dos nossos esquemas conceituais, e aqui temos o enseja para a explicação do que é o "relativismo conceitual".

Todos os objetos são dependentes dos esquemas conceituais, isto é, seu significado está condicionado à utilização de seus termos referentes em um ambiente interno numa forma linguística sistemática ao qual tais significados são relativos. Relativo, aqui, quer dizer simplesmente que o sentido do vocabulário possui como critério de significado a sua referência no interior de um esquema conceitual, sendo, assim, o significado de um conceito relativo a um determinado esquema conceitual.

Nesse ponto podemos entender porque Hilary Putnam se arrepende de ter chamado sua posição de realismo interno, preferindo o nome

${ }^{10}$ Putnam usa diversas vezes o termo 'interiorista' para designar a posição do realista interno.

Realismo interno como realismo pragmatista e o esquema conceitual: uma proposta crítica à metafísica tradicional - Alexandre de Freitas de Mello Júnior 
"realismo pragmatista" (2014, p. 174). O primeiro motivo é a confusão criada, segundo a qual a palavra "interior", da denominação "realismo interior", tem algo a ver com uma fórmula fundamentada na subjetividade para a configuração da realidade. Destarte, a realidade seria uma convenção formada a partir da subjetividade. Putnam detecta esse equívoco, apontando o aspecto central da objetividade salvaguardado no realismo interno (ou pragmatista) aludindo ao exemplo da casa em que entram os dois amigos:

Uma vez que deixamos claro como estamos a utilizar "objeto" (ou "existe"), a pergunta "Quantos objetos existem aí?" tem uma resposta que não é de maneira nenhuma uma questão de convenção. É por isso que eu digo que este tipo de exemplos não suporta o relativismo cultural (1999, p. 173).

É nesse sentido que podemos falar que o realismo pragmatista (tal como doravante chamarei o realismo interno) pode resguardar a objetividade. A objetividade, nessa acepção, está condicionada às nossas limitações mais fundamentais, tais como as características fisiológicas e o modo como a nossa racionalidade pode ser constituída, e "Absolutamente nada que digamos sobre qualquer objeto o descreve como ele é 'em si', independentemente dos seus efeitos em nós" (PUTNAM, 1992, p. 90). A objetividade descrita no realismo pragmatista é uma compreensão da condição humana no âmbito epistêmico, com a vantagem de não assumir uma posição relativista. A posição relativista é definida por Putnam da seguinte maneira: "O propósito global do relativismo, a sua própria característica definidora, é, todavia, negar a existência de qualquer noção inteligível de 'adequação' objetiva" (1992, p. 160). Nesse caso específico, o mérito do realismo pragmatista é prestar uma noção de objetividade, muito embora recuse-se a aderir à proposta segundo a qual a realidade é formada por objetos em si, independentes da mente.

\section{Conclusão}

Portanto, Putnam compreende, quando dizemos que conhecemos alguma coisa, ou que certo aspecto da realidade é objetivo, o que se quer dizer com isso é que há uma noção de verdade que pode ser preservada, apesar de se renegar uma correspondência unívoca entre as coisas (1992, p. 92). Putnam declara o seguinte:

Uma amostra de conhecimento (i.e., um "enunciado verdadeiro") é um enunciado que um ser racional aceitaria com base em experiência suficiente do gênero daquela que é de fato possível para seres com a nossa natureza. A "verdade" em qualquer outro sentido é-nos inacessível e é-nos inconcebível. A verdade é a melhor adequação que será possível atingir no limite (1992, p. 92). 
É bastante significativo que Putnam reitere a ênfase no ponto de vista de seres como nós para estabelecer o que é o conhecimento, e que o conhecimento possível a essa perspectiva é o único que pode haver. Assim, podemos entender que a referência de Putnam a essa espécie de limite quer dizer que o conhecimento humano não é incondicionado, e conceitos como objetividade, conhecimento, e verdade, estão relacionados pela circunstância naturalmente cerceada em que se encontra o gênero humano, com respeito a qual somente pode falar sobre o mundo do seu ponto de vista, e não do ponto de vista do "Olho de Deus".

Consoante a isso, os esquemas conceituais serão o cenário onde essa adequação pode ser implementada e constantemente melhorada, e isso acontece de tal maneira que podemos falar, ainda, de objetividade e verdade quando acionamos o realismo pragmatista. A concussão a que chegamos, é que o realismo pragmatista com o qual Putnam nos brinda pode impetrar o raro movimento de encetar uma crítica ao realismo da metafísica tradicional, ao mesmo tempo em que preserva uma das grandes vantagens deste, qual seja, a noção de objetividade (e verdade).

\section{Referências bibliográficas}

BLACKBURN, Simon. Dicionário Oxford de filosofia. Rio de Janeiro: Zahar, 1997.

BERNSTEIN, Richard J. The Pragmatic Turn. Cambridge: Polity Press, 2010

BRANQUINHO, João \& MURCHO, Desidério \& GONÇALVES GOMES, Nelson (Ed). Enciclopédia de Termos Lógico-Filosóficos. São Paulo, SP: Martins Fontes, 2006.

DE OLIVEIRA, Manfredo A. Reviravolta Linguístico-Pragmática. São Paulo: Edições Loyola, 2006.

DEWEY, John. Reconstrução Em Filosofia. Editora: ícone, 2012.

Associados, 2009.

A valoração das ciências humanas. Ed.: Autores Teoria da Vida Moral. In: Os Pensadores. São Paulo: Abril Cultural, 1980.

GUIDO, Imaguire \& SCHIRN, Matthias. Estudos em filosofia da linguagem. São Paulo: Edição Loyola, 2008.

JAMES, William. Pragmatismo e textos selecionados. In: Os Pensadores. São Paulo: Abril Cultural, 1974.

Motivation, Metaphysics, and the value of the

self: a reply to Ginsborg Guyer, and Schneewind. Ethics, 109, p. 49-66, outubro de1998.

KUHN, Thomas. A estrutura das revoluções científicas. 12a ed. São Paulo: Perspectiva, 2013. 
NAVIA, Ricardo. En Torno a la Polémica Habermas-Putnam sobre la Validez Racional de los Juicios Éticos y Morales. In: Dissertatio. Vol.: 35, pp. 11-30, 2012.

PUTNAM, Hilary. O colapso da verdade e outros ensaios. Aparecida, SP: Ideias \& Letras, 2008a.

Ideias \& Letras, 2008c.

Corda tripla: mente, corpo e mundo. Aparecida, SP:

Las mil caras del realismo. Barcelona: Ediciones Paidós

Ibérica, S.A., 1994.

- Representação y Realidade: Un balance crítico del funcionalismo. Barcelona: Editorial Gedisa S. A., 2014.

1999a.

Realismo de rosto humano. Lisboa: ed. Instituto Piaget,

Renovar a filosofia. Lisboa: ed. Instituto Piaget, 1999b

Razão, verdade e história. Lisboa: Publicações Dom

Quixote, 1992.

Press, 2004.

Ethics without ontology. Cambridge, Mass.: Harvard

The analytic and the synthetic. In: Mind, Language and

Reality, Philosophical Paper, Vol. 2. Cambridge: Cambridge University Press, 1975.

. 'Two dogmas' revisited In: Realism and Reason, Philosophical Paper, Vol. 3. Cambridge: Cambridge University Press, 1983.

Ibérica, 1994. Las Mil Caras del Realismo. Barcelona: Ediciones Paidós

PUTNAM, Hilary \& HABERMAS, Jürgen. Normas y valores. Introducción, traducción y notas de Jesús Vega Encabo y Javier Gil Martín Madrid: Editorial Trotta, 2008b.

RORTY, Richard. Objetivismo, Relativismo, e Verdade. Rio de Janeiro, RJ: Relume-Dumará, 1997.

. Verdade e Progresso. Barueri, SP: Manole, 2005.

. Consequências do Pragmatismo. Lisboa, PT. Instituto

Piaget, 1999.

2010.

Uma Ética Laica. São Paulo: WMF Martins Fontes,

RORTY, Richard \& ENGEL, Pascal. Para que serve a verdade? São Paulo: Editora UNESP, 2008.

VEGA ENCABO, J. \& GIL MARTÍN, J., "Introducción: Pragmatismo, objetividad normativa y pluralismo".In: PUTNAM, H. \& HABERMAS, J. Normas y valores. Madrid: Ed. Trotta, 2008.

WITTGENSTEIN, Ludwig. Investigações Filosóficas. $6^{\mathrm{a}}$ ed. - Petrópoles, RJ: Vozes, 2009.

Paulo, SP: Editora da Universidade de São Paulo, 2010. 
WITTGENSTEIN, Ludwig \& WAISMANN, Friedrich. Wittgenstein and the Vienna Circle: conversations record by Friedrich Waismann. Oxford, England: Basil Blackwell, 1979. 